\title{
PEMETAAN DAERAH PERKEBUNAN BERDASARKAN LUAS DAN JUMLAH PRODUKSI DI KALIMANTAN TENGAH BERBASIS WEB
}

\author{
Ikhsan Ma'rif, Ahmad Faisol, Nurlaily Vendyansyah \\ Program Studi Teknik Informatika S1, Fakultas Teknologi Industri \\ Institut Teknologi Nasional Malang, Jalan Raya Karanglo km 2 Malang, Indonesia \\ 1618119@scholar.itn.ac.id
}

\begin{abstract}
ABSTRAK
Di Kalimantan Tengah yang memliki ibu kota di Palangkaraya yang memiliki kekayaan alam dibidang perkebunan yang mana memiliki luas $153.564,60 \mathrm{~km}$ yang tentunya di manfaatkan oleh masyarakat yang berada di Kalimantan Tengah untuk melakukan kegiatan pada bidang perkebunan. Kelapa Sawit merupakan produk unggulan di Kalimantan Tengah yang pada tahun produktivitasnya kelapa sawit mencapai 4,09 ton per ha dengah jumlah tenaga kerja sebanyak 762.573 orang. Dilihat dari luasnya perkebunan di Kalimantan Tengah masyarakat masih banyak yang belum mengetahui informasi berapa luas dan jumlah produksi yang terdapat di Kalimantan tengah.

Dengan permasalahan itu tulisan ini dibuat untuk membahas tentang informasi luas dan jumlah produksi dari komoditas perkebunan di Kalimantan Tengah yang tersebar di 13 kabupaten dan 1 kota antara lain Palangkaraya, Kotawaringin Timur, Kotawaringin Barat, Kapuas, Gunung Mas, Barito Timur, Barito Utara, Barito Selatan, Katingan, Seruyan, Sukamara, Pulang Pisau, Lamandau, dan Murung Raya. Dan terdapat 12 komoditas antara lain kelapa sawit, karet, kelapa, aren, cengkeh, jambu mete, kakao, kapuk randu, kemiri, kopi, lada, dan pinang. Manfaat dari sistem informasi geografis berbasis web ini adalah untuk pemetaan perkebunan berdasarkan luas dan jumlah produksi di Kalimantan Tengah.

Hasil pengujian Fungsional sudah berjalan sesuai dengan kebutuhan aplikasi. Hasil pengujian fungsional pada website menunjukan hasil $100 \%$ sesuai dengan desain. Hasil pengujian fungsional pada mobile menunjukan hasil $100 \%$ sesuai dibuktikan dengan tata letak tampilan yang sesuai dengan desain.
\end{abstract}

Kata Kunci : Sistem Informasi Geografis, Komoditas Perkebunan,Pemetaan, Kalimantan Tengah, Website

\section{PENDAHULUAN}

Wilayah Indonesia mempunyai sumber daya alam yang sangat begitu melimpah yang salah satunya terletak di daerah Kalimantan Tengah yang memiliki ibu kota di Palangkaraya dan juga merupakan provinsi terluas ke 2 di Indonesia yang memiliki kekayaan alam dibidang perkebunan, pariwisata, pertanian, pertambangan, perikanan dan dibeberapa sector lainnya. Yang paling menonjol diantara yang lainnya adalah pada bidang perkebunannya, yang mana memiliki luas 153.564,60 $\mathrm{km}$ dengan hutannya yang masih sangat luas dan hijau yang tentu saja dimanfaatkan oleh masyarakat Kalimantan Tengah untuk melakukan kegiatan pada bidang perkebunan. Kelapa sawit merupakan produk unggulan dari provinsi Kalimantan Tengah yang pada tahunnya produktivitas kelapa sawit mencapai 4,09 ton per ha dengan jumlah tenaga kerja sebanyak

762.573 orang. Angka tersebut jauh lebih tinggi dibandingkan produktivitas rata-rata Indonesia yang hanya sekitar 2,92 ton per ha, sedangkan Indonesia berpotensi mencapai 25 ton per ha CPO di areal sawit tersebut.

Dilihat dari luasnya perkebunan di Kalimantan Tengah, Dinas Perkebunan Kalimantan Tengah merancang peta kawasan perkebunan. Namun tidak semua masyarakat khususnya masyarakat di Kalimantan Tengah mengetahui informasi berapa luas masing-masing perkebunan dan jumlah produksidari masing-masing perkebunan tersebut untuk itu dengan adanya sistem informasi geografis ini nantinya mampu memberikan informasi-informasi yang dibutuhkan mengenai pemetaan sebuah data dari komoditas perkebunan sehingga masyarakat akan mudah mengetahui informasi geografis sebuah perkebunan apa saja yang terdapat di Kalimantan Tengah karena diakses melalui jaringan internet yang tentunya lebih akurat dan mudah di akses.

Dengan adanya penelitian mengenai Sistem Informasi Geografis Pemetaan daerah perkebunan berdasarkan luas dan jumlah produksi di Kalimantan Tengah ini diharapkan mampu memberikan informasi agar masyarakat khususnya masyarakat di Kalimantan Tengah dapat mengetahui peluangpeluang yang bisa di hasilkan dari jenis perkebunan yang memiliki jumlah produksi terbanyak.

\section{TINJAUAN PUSTAKA}

\subsection{Penelitian Terdahulu}

Pada tahun 2018 Pranoto dkk melakukan penelitian mengenai pemetaan berbasis website untuk pusat kesehatan masyarakat di wilayah Kabupaten Malang. Penelitian tersebut memetakan pusat kesehatan yang ada di kabupaten malang dalam bentuk website. [1] 
Pada tahun 2009 Fie Jannatin Aliyah melakukan penelitian mengenai Sistem Informasi Geografis Berbasis Web Mengenai Penyebaran FasilitaPendidikan, Perumahan Dan Rumah Sakit Di Kota Bekasi. Penelitian tersebut memetakan penyebaran fasilitas pendidikan, perumahan dan rumah sakit dalam bentuk web.

Kemudian pada tahun 2016 Zulafwan melakukan penelitian Sistem Infomasi Geografis Pemetaan Perkebunan Sawit Berbasis Web. Penelitian ini memberikan manfaat kepada kabupaten Pasman Barat yaitu memberikan informasi yang lebih akurat dan mudah didapat mengenai perkebunan kelapa sawit yang ada di kabupaten Pasaman Barat ke masyarakat luas.[3]

Pada tahun itu pula Webie Ni Maja Dj dan Agung Budi Cahyono melakukan penelitian Perancangan Sistem Informasi Geografis Zona Nilai Tanah Berbasis Web Menggunakan Leaflet Javascript Library dengan studi kasus Kecamatan Kenjeran, Kecamatan Gubeng, Kecamatan Tambak Sari dan Kecamatan Bulak, Kota Surabaya, Jawa Timur. Penelitian tersebut mampu menghasilkan Produk WebGIS yang memenuhi keperluan pemercepat proses pembaharuan data nilai tanah.[4]

Kemudian pada tahun berikutnya yaitu tahun 2017 mambang melakukan penelitian mengenai system informasi geografis pemetaan hasil perkebunan dan pertanian. Penelitian tersebut membantu dalam menentukan lokasi pertanian dan perkebunan di Kabupaten Banjar sehingga tidak sulit untuk melakukan peninjauan ke lokasi, selain itu aplikasi ini juga berfungsi untuk membantu dalam mengelola data dan menganalisa hasil pertanian dan perkebunan apakah mengalami peningkatan atau penurunan.[5]

Pada Tahun yang sama yaitu tahun 2017 M. Ibnu Wardana dan Muhammad Jazman Julkifli melakukan penelitian mengenai Rancang Bangun Sistem Informasi Geogafis Pemetaan Ruang Ujian Menggunakan Bootstrap dan Leaflet.js di Fakultas Sains dan Teknologi UIN Suska Riau. Dengan adanya penelitian tersebut menghasilkan yaitu SIG Pemetaan ruangan ini Fakultas Sains dan Teknologi dapat menerapkan teknologi di bidang gis yang baru, harapannya bisa mengadaptasi teknologi baru dengan cepat.[6]

\subsection{Sistem Informasi Georagrafis}

Menurut Dewi Handayani U.N, R.Soelistijadi dan Sunardi Sistem Informasi Geografi (SIG) merupakan sistem informasi berbasis komputer yang digunakan secara digital untuk menggambarkan dan menganalisa ciri-ciri geografi yang digambarkan pada permukaan bumi dan kejadian-kejadiannya (atributatribut non spasial untuk dihubungkan dengan studi mengenai geografi).

Sistem Informasi Geografi menghasilkan aspek data spasial dan data non spasial. Data geografi yang sudah komputerisasi berperan penting menemukan perubahan bagaimana menggunakan dan mengetahui informasi tentang bumi.[7]

\subsection{Web Situs/Website}

Website merupakan sebuah media informasi yang ada di internet. Website tidak hanya dapat digunakan untuk penyebaran infomasi saja melainkan bisa digunakan untuk membuat toko online. Website adalah kumpulan dari halaman-halaman situs, yang biasanya terangkum dalam sebuah domain atau subdomain, yang tempatnya berada di dalam World Wide Web (WWW) di Internet. Sebuah halaman web adalah dokumen yang ditulis dalam format HTML (Hyper Text Markup Language), yang hampir selalu bisa diakses melalui HTTP, yaitu protokol yang menyampaikan informasi dari server website untuk ditampilkan kepada para pemakai melalui web browser.[10]

\subsection{PHP}

PHP merupakan salah satu bahasa pemograman berbasis web dimana sistem yang diterapkan adalah pada sisi server side. PHP dapat disisipkan diantara skrip-skrip bahasa $H T M L$ dan arena bahasa server side lainnya, dengan itu maka $P H P$ akan dieksekusi secara langsung pada server. Sedangkan browser akan mengeksekusi halaman web tersebut melalui server yang kemudian akan menerima tampilan "hasil jadi" dalam bentuk $H T M L$, sedangkan kode $P H P$ itu sendiri tidak akan dapat terlihat.[9]

\subsection{Leaflet}

Menururt Webie Ni Maja Dj dan Agung Budi Cahyono,(2016) bahwa Leaflet merupakan JavaScript Library tidak berbayar (open source) pertama untuk pembuatan peta interaktif mobile yang bersahabat. Dengan ukuran kira-kira $33 \mathrm{~KB}$, tetapi itu telah mencangkup seluruh fitur-fitur membuat peta yang dibutuhkan oleh pengembang atau pembuat peta berbasis web.

Leaflet didesain dengan kemudahan dalam penggunaan, performa yang baik dan kebermanfaatan tinggi. Leaflet bekerja secara efisien untuk seluruh platforms mobile dan desktop, dapat diintegrasikan dengan banyak plugin, memiliki desain yang indah, mudah digunakan, simpel dan sumber kode yang mudah dibaca.[4]

\subsection{GeoJSON}

Menururt M. Ibnu Wardana, Muhammad Jazman, (2017) dalm jurnalnya Geojson merupakan format data yang berbasis JSON (Javascript Object Notation) dan dapat menampung unsur-unsur geografis. Kelebihannya adalah kompatibel dengan banyak model pemrograman pada peta, dapat digunakan pada leaflet.js dan google maps.

GeoJSON dapat ditarik dan ditampilkan dengan Leaflet Javascript engine, serta bersifat vektor, artinya ketika di zoom tidak akan pecah. Format data lain yang bisa ditarik dan ditampilkan dengan Leaflet 
Js engine antara lain Web Feature Service, Web Map Service dan Postgis.[6]

\section{METODE PENELITIAN}

\subsection{Rancangan Teknologi Yang Akan} Dikembangkan

Rancangan teknologi yang akan dikembangkan sistem ini menjelaskan rancangan dari aplikasi yaitu:

1. Sistem dapat menampilkan data-data berupa peta luas dan jumlah produksi perkebunan di Kalimantan Tengah.

2. Sistem membaca,mengubah,memperbarui mampu menghapus data.

3. Pembeda antara Komoditas di peta akan ditandai dengan perbedaan warna.

4. Halaman untuk admin terdiri dari Home, About, Info

5. Halaman Home admin terdapat fitur untuk merubah , membuat dan menghapus data.

6. Admin bisa mengakses semua halaman dan dapat melakukan CRUD yaitu Create(membuat),

Read(membaca),Update(merubah),Delete(me ngha pus), yang nantinya akan di lakukan di halaman Home admin

7. Halaman user terdiri dari Home, About, Info dan Login Sebagai admin.

8. User disini hanya bisa melihat halaman dan tidak bisa melakukan perubahan ,penambahan ataupun hapus data karena fungsi merubah, menambah dan menghapus adalah fungsi dari admin.

\subsection{Blok Diagram Sistem}

Blok diagram adalah diagram dari sebuah sistem, dimana terdapat input, proses dan output. Pada input terdapat data spasial Komoditas, data atribut komoditas, dan data wilayah. Pada diagram blok dimana input terdiri dari pengumpulan data, proses merupakan suatu alur mengorganisasikan data, dan kemudian pada output akan menampilkan hasil keluran data seperti table, grafik, dan peta.

Proses kerja sistem informasi geografis di tunjukkan pada Gambar 1.

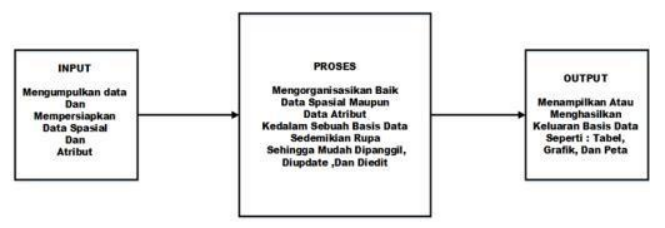

Gambar 1. Blok diagram sistem

\subsection{Flowchart Sistem}

Flowchart sistem ini menjelaskan proses berjalananya sistem seperti ditunjukkan pada Gambar 2.

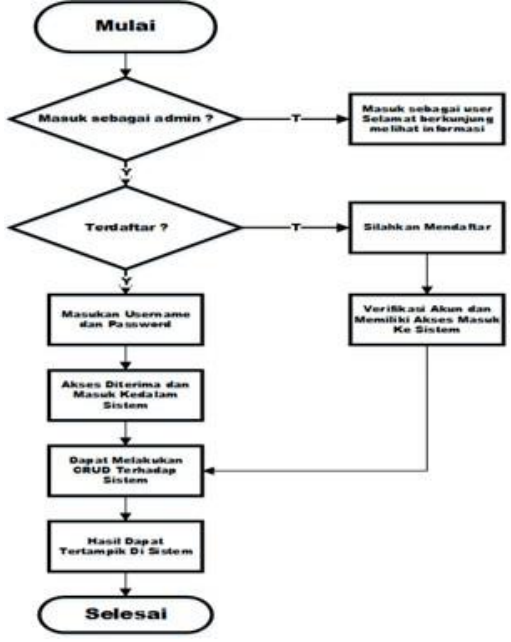

Gambar 2. Flowchart Sistem

Gambar 3. Flowchart sistem dimana awal mulai kita di suguhkan dengan login sebagai user atau sebagai admin, apabila kita memilih sebagai user maka user hanya bisa melihat informasi sedangkan apa bila masuk sebagai admin, admin mampu melakukan CRUD yaitu Create(membuat), Read(membaca),Update(Merubah),Delete(menghapu s), dari system dan tentunya harus mendaftar sebagai admin dulu agar bisa masuk.

\section{HASIL DAN PEMBAHASAN}

\subsection{Hasil}

Hasil dari program untuk tampilan pada halaman Home (depan) dapat ditunjukkan dalam Gambar 3.

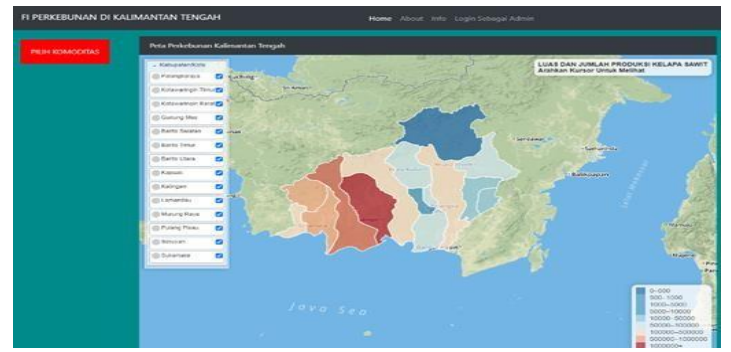

Gambar 3. Halaman Home

Hasil dari program untuk tampilan pada panel layer dapat ditunjukkan dalam Gambar 4.

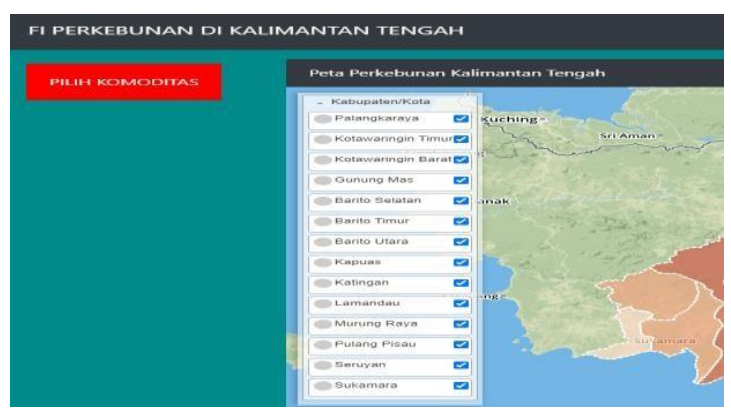

Gambar 4. Tampilan Panel Layer 
Hasil dari program untuk tampilan Pilih Komoditas dapat ditunjukkan dalam Gambar 5.

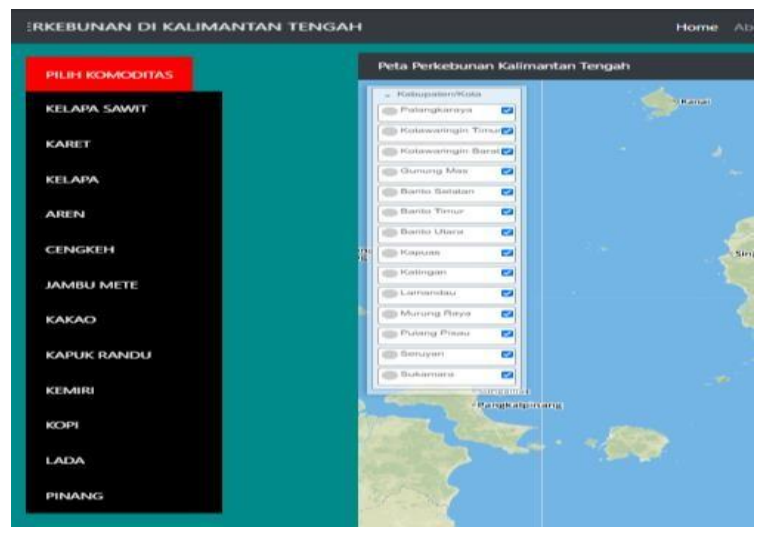

Gambar 5. Pilih Komoditas

Hasil dari program untuk tampilan pada halaman About dapat ditunjukkan dalam Gambar 6.

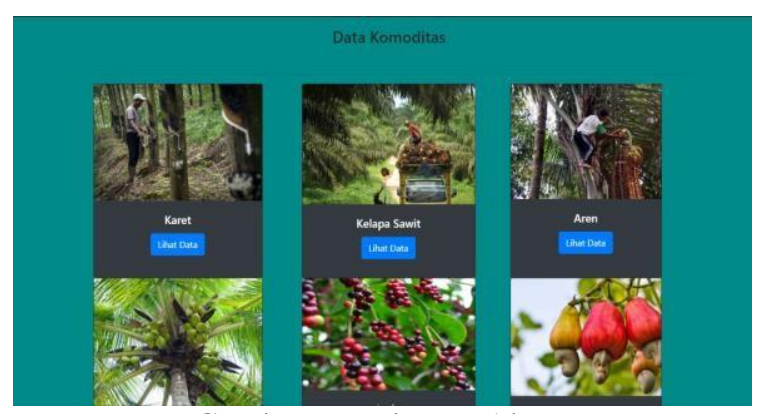

Gambar 6. Halaman About

Hasil dari program untuk tampilan Halaman Info dapat ditunjukkan dalam Gambar 7.

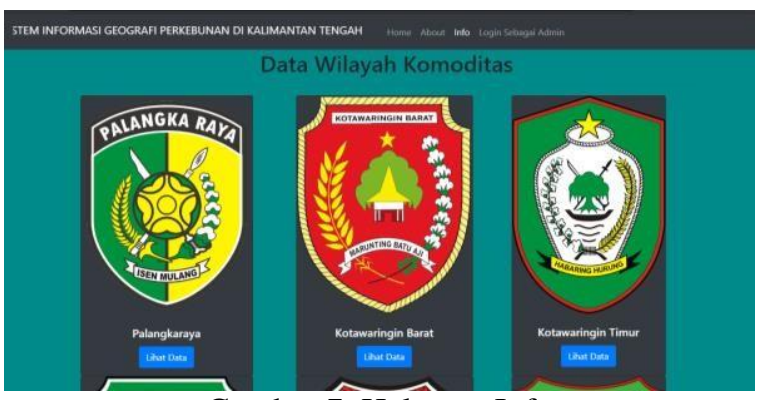

Gambar 7. Halaman Info

Hasil dari program untuk tampilan Data Komoditas dapat ditunjukkan dalam Gambar 8.

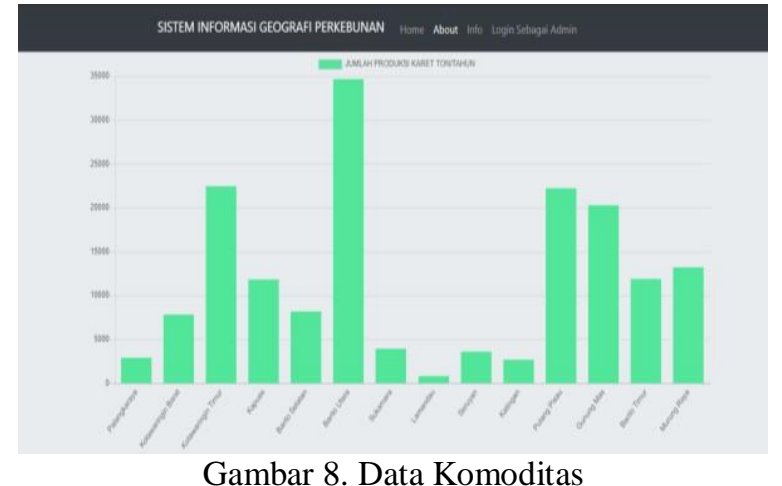

Hasil dari program untuk tampilan Data Wilayah dapat ditunjukkan dalam Gambar 9.

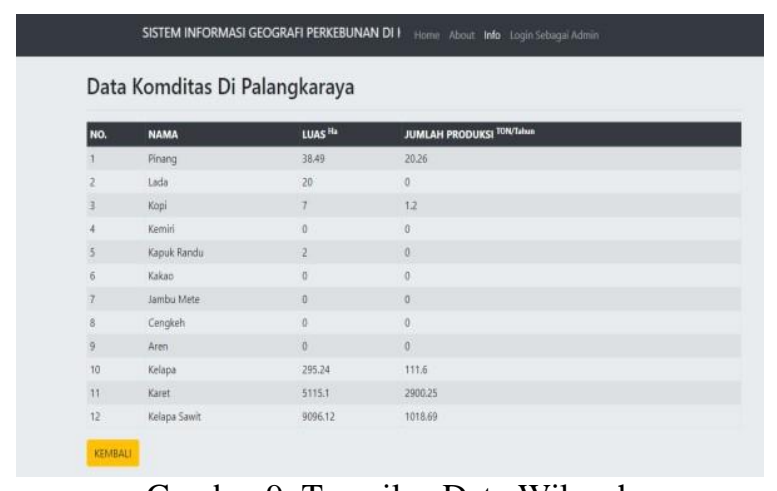

Gambar 9. Tampilan Data Wilayah

Hasil dari program untuk tampilan pada halaman Data Wiayah Admin Gambar 10.

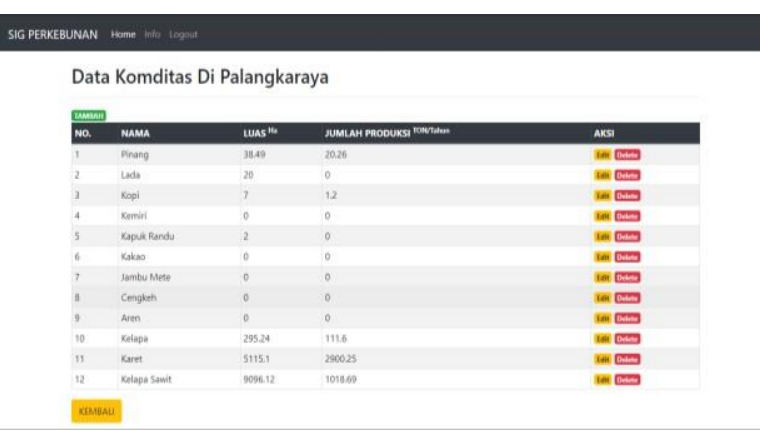

Gambar 10. Tampilan Data Wilayah Admin

\subsection{Pengujian Fungsional}

Pengujian fungsional dilakukan untuk mengetahui apakah fungsi sudah sesuai dengan kebutuhan atau belum. Pengujian ini juga dilakukan untuk mengatasi error dan menguji validation yang seringkali dilakukan tidak sesuai dengan ketentuan penggunaan aplikasi. 
Tabel 1. Pengujian fungsi menggunakan website

\begin{tabular}{|c|l|r|r|r|}
\hline \multirow{2}{*}{$\begin{array}{c}\text { Hak } \\
\text { Akses }\end{array}$} & Fungsional & \multicolumn{3}{|c|}{ Browser } \\
\cline { 2 - 5 } & Chrome & Edge & Opera \\
\hline \multirow{5}{*}{ User } & Home & OK & OK & OK \\
\cline { 2 - 5 } & About & OK & OK & OK \\
\cline { 2 - 5 } & Info & OK & OK & OK \\
\cline { 2 - 5 } & $\begin{array}{l}\text { Data } \\
\text { Komoditas }\end{array}$ & OK & OK & OK \\
\cline { 2 - 5 } & $\begin{array}{l}\text { Data } \\
\text { Wilayah }\end{array}$ & OK & OK & OK \\
\hline \multirow{5}{*}{ Admin } & Info admin & OK & OK & OK \\
\cline { 2 - 5 } & $\begin{array}{l}\text { Edit } \\
\text { Komoditas }\end{array}$ & OK & OK & OK \\
\cline { 2 - 5 } & $\begin{array}{l}\text { Delete } \\
\text { Komoditas }\end{array}$ & OK & OK & OK \\
\cline { 2 - 5 } & $\begin{array}{l}\text { Tambah } \\
\text { Komoditas }\end{array}$ & OK & OK & OK \\
\hline
\end{tabular}

Pada Tabel 1 Pada pengujian Fungsional 100\% sudah berjalan sesuai dengan kebutuhan aplikasi yang dilakukan oleh browser Chrome, Edge, dan Opera.

Tabel 2 Pengujian fungsi menggunakan Browser pada perangkat mobile

\begin{tabular}{|c|c|c|c|}
\hline \multirow[b]{2}{*}{$\begin{array}{c}\text { Hak } \\
\text { Akses }\end{array}$} & \multirow[b]{2}{*}{ Fungsional } & \multicolumn{2}{|c|}{ Browser } \\
\hline & & $\begin{array}{c}\text { Chrome } \\
\text { V. } \\
81.0 .4044\end{array}$ & $\begin{array}{l}\text { Browser } \\
\text { V.11.11. } \\
22\end{array}$ \\
\hline & Home & OK & OK \\
\hline & Info & $\mathrm{OK}$ & $\mathrm{OK}$ \\
\hline & About & OK & $\mathrm{OK}$ \\
\hline & $\begin{array}{l}\text { Data } \\
\text { Komoditas }\end{array}$ & $\mathrm{OK}$ & $\mathrm{OK}$ \\
\hline & Data Wilayah & OK & OK \\
\hline \multirow{4}{*}{ Admin } & Info admin & $\mathrm{OK}$ & $\mathrm{OK}$ \\
\hline & $\begin{array}{l}\text { Edit } \\
\text { Komoditas }\end{array}$ & $\mathrm{OK}$ & $\mathrm{OK}$ \\
\hline & $\begin{array}{l}\text { Delete } \\
\text { Komoditas }\end{array}$ & $\mathrm{OK}$ & $\mathrm{OK}$ \\
\hline & $\begin{array}{l}\text { Tambah } \\
\text { Komoditas }\end{array}$ & $\mathrm{OK}$ & $\mathrm{OK}$ \\
\hline
\end{tabular}

Pada Tabel 2. Pengujian fungsi menggunakan Browser pada perangkat mobile Fungsional 100\% sudah berjalan sesuai dengan kebutuhan aplikasi yang dilakukan oleh browser di mobile Chrome dan Browser. Dibuktikan dengan tata letak tampilan yang sesuai untuk mobile.

\section{KESIMPULAN DAN SARAN \\ 5.1 Kesimpulan}

Berdasarkan analisa yang telah di lakukan pada sistem informasi geografis pemetaan daerah perkebunan berdasarkan luas dan jumlah produksi berbasis web di kalimantan tengah pada bab sebelumnya maka dapat diambil kesimpulan sebagai berikut :

1. Hasil pengujian fungsional menunjukkan hasil
$100 \%$ dapat berjalan dengan baik di Google Chrome, Edge, dan Opera.

2. Hasil pengujian fungsional pada perangkat mobile menunjukkan hasil 100\% dibuktikan dengan tata letak tampilan yang sesuai.

\subsection{Saran}

Beberapa saran dari penulis agar sistem informasi geografis ini mampu berfungsi sesuai dengan tujuan sistem ini dibangun, diantaranya:

1. Untuk pengembangan kedepanya, sistem informasi geografis ini terdapat versi mobile.

2. Untuk kedepanya bisa di tambahkan metode untuk pengelompokan komoditas.

\section{DAFTAR PUSTAKA}

[1] Y. A. Pranoto, M. M. Rokhman and S. A. Wibowo, "APLIKASI PEMETAAN BERBASIS WEBSITE UNTUK PUSAT KESEHATAN," Jurnal MNEMONIC, vol. I, no. 1, pp. 50-55, 2018.

[2] F.J. Aliyah, "SISTEM INFORMASI GEOGRAFIS BERBASIS WEB MENGENAI PENYEBARAN FASILITAS PENDIDIKAN, PERUMAHAN, DAN RUMAH SAKIT DI KOTA BEKASI", 2019. Zulafwan, "SISTEM

GEOGRAFIS

INFORMASI PERKEBUNAN

[3] SAWIT BERBASIS WEB," Riau Journal Of Computer Science Vol.2 No.2 : 7 - 16, 2016.

[4] W. N. M. Dj, A. B. Cahyono, "PERANCANGAN SISTEM INFORMASI GEOGRAFIS ZONA NILAI TANAH BERBASIS WEB MENGGUNAKAN LEAFLET JAVASCRIPT LIBRARY," jurnal teknik ITS Vol. 5, No. 2, ISSN: 2337-3539, 2016.

[5] Mambang, "SISTEM INFORMASI GEOGRAFIS HASIL PEMETAAN PERTANIAN,"

[6] Konferensi Nasional Sistem \& Informatika STMIK STIKOM Bali, 2017.

[7] M. I. Wardana, M. Jazman, "RANCANG BANGUN SISTEM INFORMASI GEOGAFIS PEMETAAN RUANGUJIAN MENGGUNAKAN BOOTSTRAP DAN LEAFLET.JS," Seminar Nasional Teknologi Informasi, Komunikasi dan Industri (SNTIKI) 9, Fakultas Sains dan Teknologi, UIN Sultan Syarif Kasim Riau, 2017.

[8] D. Handayani U.N, R. Soelistijadi, Sunardi, "PEMANFAATAN ANALISIS SPASIAL UNTUK PENGOLAHAN DATA SPASIAL SISTEM INFORMASI GEOGRAFI,” 2018. 
Jurnal Teknologi Informasi DINAMIK Volume X, No.2, 2005.

[9] H. Zarodi, M. Anshori, F. Asisi, S. Widanto, "PEMANFAATAN WEBGIS DALAM MENDUKUNG PROGRAM DESA BERSAUDARA DI KABUPATEN MAGELANG," Seminar Nasional Geomatika 2017: Inovasi Teknologi Penyediaan Informasi Geospasial untuk Pembangunan Berkelanjutan, 2017
[10] KM. S. Haryana, "PENGEMBANGAN PERANGKAT LUNAK DENGAN MENGGUNAKAN PHP," Jurnal Computech \& Bisnis, Vol. 2, No. 1, 14-21, ISSN 1978-9629, 2008.

[11] Y. Trimarsiah, M. Arafat, "ALISIS DAN PERANCANGAN WEBSITE SEBAGAI SARANA INFORMASI PADA LEMBAGA BAHASA KEWIRAUSAHAAN DAN KOMPUTER AKMI BATURAJA," Jurnal Ilmiah MATRIK Vol.19 No.1: 1-10, 2017 